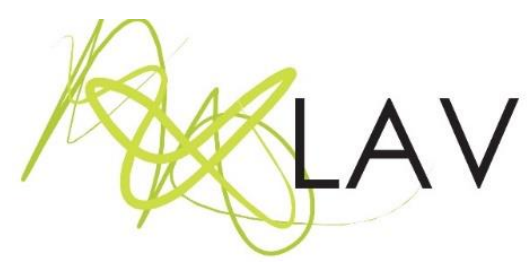

\title{
Notas acerca das ressonâncias de um processo de iniciação artística na criação de si
}

Notes on the resonances of an artistic initiation process on the creation of the self

Ana Cristina Rossetto Rocha ${ }^{i}$

Musicista, educadora musical e pesquisadora

\begin{abstract}
Resumo
Um conjunto de entrevistas realizadas com ex-alunos da Escola Municipal de Iniciação Artística (São Paulo, SP) constituiu o material de pesquisa da minha tese de doutorado. Ela investiga a atuação da memória como dispositivo de ressignificação e a potência da iniciação artística como campo propício às práticas do cuidado de si - noção que atravessou a cultura e a filosofia greco-romana por um período de longa duração e foi retomada por Foucault nos seus últimos trabalhos. A abordagem cartográfica, referenciada no conceito de cartografia de Deleuze e Guattari oferece a principal orientação metodológica. Compartilhar recortes deste trabalho relacionando-os à temática deste dossiê é o objetivo deste artigo.
\end{abstract}

Palavras-chave cartografia, arte-educação, cuidado de si, memória, narrativa.

\begin{abstract}
A set of interviews with former students from Escola Municipal de Iniciação Artística (Municipal School of Artistic Initiation) (São Paulo, SP) constitutes the material of my PhD thesis. It investigates the role of memory as a device of resignification and the potency of artistic initiation as a favorable field to the practices of the care of the self - notion that crossed culture and greco-roman philosophy for a long period and was recovered by Foucault in his later works. The cartographic approach, referred in Deleuze and Guattari's cartography concept, offers methodological guidance. Sharing excerpts of this paper by relating them to the theme of this dossier is the purpose of this article.
\end{abstract}

Keywords cartography, artistic education, care of the self, memory, narrative.

Enviado em: 01/06/18 - Aprovado em: 17/07/18

\section{Dois recortes de abertura}

Do conjunto de entrevistas que constituiu o material de pesquisa do meu doutorado, inicio este texto com dois recortes dos relatos de Carolina, educadora musical e musicistabrincante, e Júlia, artista e professora de artes visuais.

Revista Digital do LAV - Santa Maria - vol. 11, n. 2, p. 40 - 61 - mai./ago. 2018 ISSN 1983 - 7348

http://dx.doi.org/10.5902/1983734833896 
O mais importante da EMIA foi ser um espaço de liberdade para criar. Tudo está ficando tão formatado, não te dão espaço para criar. Ou dão de um jeito limitado, dentro de uma lógica de mercado (Carolina).

Criar traz uma coisa a mais para o ser humano. Não é só trabalhar quinze horas por dia e pronto; [...]. Viver é muito chato; criar não. É o que dá sentido à existência [...]. Ensinar arte exige crer na arte, crer no mundo visível (Júlia).

Ambas, ex-alunas da EMIA - Escola Municipal de Iniciação Artística, serão posteriormente apresentadas, assim como a própria escola. Também o problema que gerou a pesquisa será abordado com mais cuidado. Por ora, coloco em linhas amplas o mote provocador da investigação: pode um processo de iniciação artística fomentar, no curso de uma vida, modos de existência implicados na criação de si? Tal indagação foi instigada pelo conjunto de estudos e análise nos quais Michel Foucault (FOUCAULT, 2011) aborda as práticas que envolviam na cultura grega e romana a noção do cuidado de $s i^{1}$. A abordagem de Foucault não propõe, de modo algum, uma espécie de resgate do passado. Ao revés, constitui-se numa provocação para pensarmos em nosso próprio tempo as formas e os modos das relações pelas quais o indivíduo se constitui e se relaciona com os outros e consigo mesmo.

Por esta perspectiva, a minha indagação acerca da influência que as experiências estéticas e artísticas vividas na infância poderiam exercer nessa busca de uma criação de si, de uma "estética da existência" (FOUCAULT, 2010, p. 290) não se dirigia, necessariamente, a alunos que tivessem se tornado professores da área artística. Porém, como duas das entrevistadas eram professoras (Carolina de música, Júlia de artes visuais), essa temática emergiu por si, sem que perguntas específicas fossem sido feitas.

\section{Das inquietações de uma professora}

"Buscamos apenas determinar o sentido preciso que nossa consciência dá à palavra "existir" e descobrimos que, para um ser consciente, existir consiste em mudar, mudar, em amadurecer, amadurecer, em criar-se indefinidamente a si mesmo. Poder-se-ia dizer o mesmo da existência em geral"?

(Henri Bergson)

Por que há questões que tanto nos inquietam? Por que a elas não bastam as respostas que respaldados por nossa prática e nossas reflexões podemos formular com relativa

\footnotetext{
${ }^{1}$ De uma perspectiva ampla, a noção do cuidado de si toma a filosofia como prática de vida, implicada em uma ética, no governo de si e no exercício da liberdade.
} 
facilidade? Menos ainda nos valem as respostas que o senso comum pode oferecer, sem demandar de nós custo ou esforço, pois, simplistas e pobres em harmônicos, não vibram nem ecoam - esgotam o assunto e fazem murchar qualquer movimento de expansão do pensamento.

São questões que ressoam em nós e nos interpelam. Seu enfrentamento "exige de nós um devir outro - entre o que somos e sabemos e o que ainda não somos, não sabemos, o que ainda não existe" (ROCHA, 2017, p. 23). Elas nos colocam diante da necessidade de mudança - e, se atendermos a este chamado, poderemos experenciar uma possibilidade de mudança e transformação.

Assim me povoavam questões relacionadas à ressonância das experiências estéticas vividas na infância no decorrer da vida de uma pessoa. Questões que me pareciam amplas e abstratas demais, mas que a todo momento atravessavam o meu cotidiano como professora de música em uma escola de arte, fazendo com que volta e meia eu me interrogasse: para além das reafirmações e certezas a respeito do valor da arte na educação e na formação dos indivíduos, que ressonância teria essa experiência no decorrer da vida dos alunos?

Envolvida na definição do foco da minha pesquisa de doutorado, as memórias de ex-alunos foram se impondo como fonte de pesquisa. Uma escolha, sim, mas de qualidade tal - não apenas de ordem mental e racional - que se manifestava quase como uma exigência: seriam as memórias dos ex-alunos da Escola Municipal de Iniciação Artística - EMIA, o material da pesquisa. Pois há a escolha, mas também hão de haver as circunstâncias e personagens que configurem as possibilidades. Há de haver "uma hora, uma ocasião, circunstâncias, paisagens e personagens, condições e incógnitas da questão" (DELEUZE; GUATTARI, 1997, p. 10). Assim comigo se passou: tramaram-se as linhas da minha vida e as variáveis que configuraram a ocasião e mesmo a sua necessidade.

Fui professora de música da EMIA por trinta e três anos. Hoje, percebo essa longa passagem como possibilidade e escolha recriadas cotidianamente. Talvez porque a cada ano eu re-começasse, com novas turmas e novos alunos, o tempo passava, mas os anos pareciam não se acumular. Entre as crianças e os colegas parceiros, absorvida por nossas experiências e criações, pude viver um tempo em contínua renovação.

Coexistindo com essa dimensão de um tempo sempre novo, experenciada nos encontros cotidianos com as crianças, a dimensão do tempo de Cronos, porém, me confrontava sim, havia um tempo que passava, e de maneira inequívoca! O tempo da minha 
aposentadoria se aproximava e eu me preparava para viver essa espécie de passagem. Uma passagem não apenas burocrática ou profissional, mas, também, de natureza existencial. Antevendo o tempo de me tornar uma ex-professora, meu olhar passou a se demorar na observação dos ex-alunos da escola.

Nos encontros com ex-alunos de vários tempos de EMIA, em eventos, visitas ou encontros casuais, defrontava-me com adultos, alguns muito jovens, outros mais maduros, às vezes acompanhados de seus filhos. Vivendo estações diversas da existência, todos, entretanto, parecendo muito diferentes ao mesmo tempo em que muito próximos das crianças que eu havia conhecido. Tocada pelos afetos que se expressavam entre ex-alunos e professores, observava uma qualidade afetiva que não se manifestava apenas entre os ex-alunos e aqueles que tinham sido seus professores diretamente - percebia um sentido de pertencimento e união que atravessava o conjunto de ex-alunos e professores: um sentido vivo de comunidade.

Paradoxalmente, em meio a essas manifestações que pareciam afirmar a força de um trabalho coletivo no qual me sentia inserida, sentia em mim, a pulsação de um problema:

A vida, a força da vida, é aquela que transforma os obstáculos em meios, meios de desenvolvimento. Este processo está na base da invenção do homem. O homem conduz a vida ao seu paroxismo: exalta-a, expande-a. Sobretudo quando a vida Ihe dá condições de possibilidade para a criação dos problemas. E o problema não é uma deficiência do conhecimento, muito mais que isso - o problema é aquilo que penetra nos horizontes para torná-los ilimitados e sempre, invariavelmente, a serviço da vida. O homem, com o rigor da matemática e a inventividade das artes, produz problemas e vai além de qualquer limite; é esta a natureza do meu trabalho: mostrar o rigor e a beleza da criação humana - mostrar sua potência em problematizar (ULPIANO, 2017, Manuscrito 14).

Pude experimentar que um problema "é sempre uma singularidade, por sua vez composto por um agenciamento de singularidades" (GALLO, 2012, p. 72), ao sentir e perceber um problema que aparentemente só a mim intrigava: no mundo real, defrontando-se com os desafios de uma sociedade competitiva, em um tempo vertiginoso que parece nada conservar, poderiam as memórias de iniciação artística se configurar como memórias produtoras de sentido?

Engajada no cotidiano da EMIA, participando do jogo de relações e opiniões que envolve o ambiente de uma escola e comprometida com os fazeres e afazeres de uma professora, não me sentia disponível para esse exercício. Foi ao me afastar, ao me aposentar, que pude começar a disfrutar de certo olhar estrangeiro e me disponibilizar à pesquisa.

Revista Digital do LAV - Santa Maria - vol. 11, n. 2, p. 40 - 61 - mai./ago. 2018 ISSN 1983 - 7348 http://dx.doi.org/10.5902/1983734833896 
No meu último ano como professora da escola, me despedi várias vezes. Das crianças, dos colegas, dos funcionários, dos pais dos alunos.... Entre uma e outra ponta do tempo, o tempo se desenrolou em velocidades variadas. Tempos de expansão, de sonhar e projetar, alternaram-se a tempos mais mornos, ou mesmo de desmanchamento de construções e projetos. Mas entre todos esses ciclos vividos, as crianças sempre estiveram lá, e os nossos encontros eram sempre recomeço. Eu não vi o tempo passar. $\mathrm{E}$, a bem da verdade, como bem aprendi com esta pesquisa, nós não vemos mesmo o tempo passando porque passamos junto com ele.... Nossa duração o acompanha, coexistimos com ele. Assim, trago todo esse tempo comigo (ROCHA, 2017, p. 56).

Ao me despedir das crianças ganhei muitos desenhos, incluindo vários retratos. Interessante como elas gostam de fazer o nosso retrato não para guardar com elas, mas para nos dar de presente. Elas nos presenteiam com a nossa própria imagem - a nossa imagem, recriada pelo seu olhar.

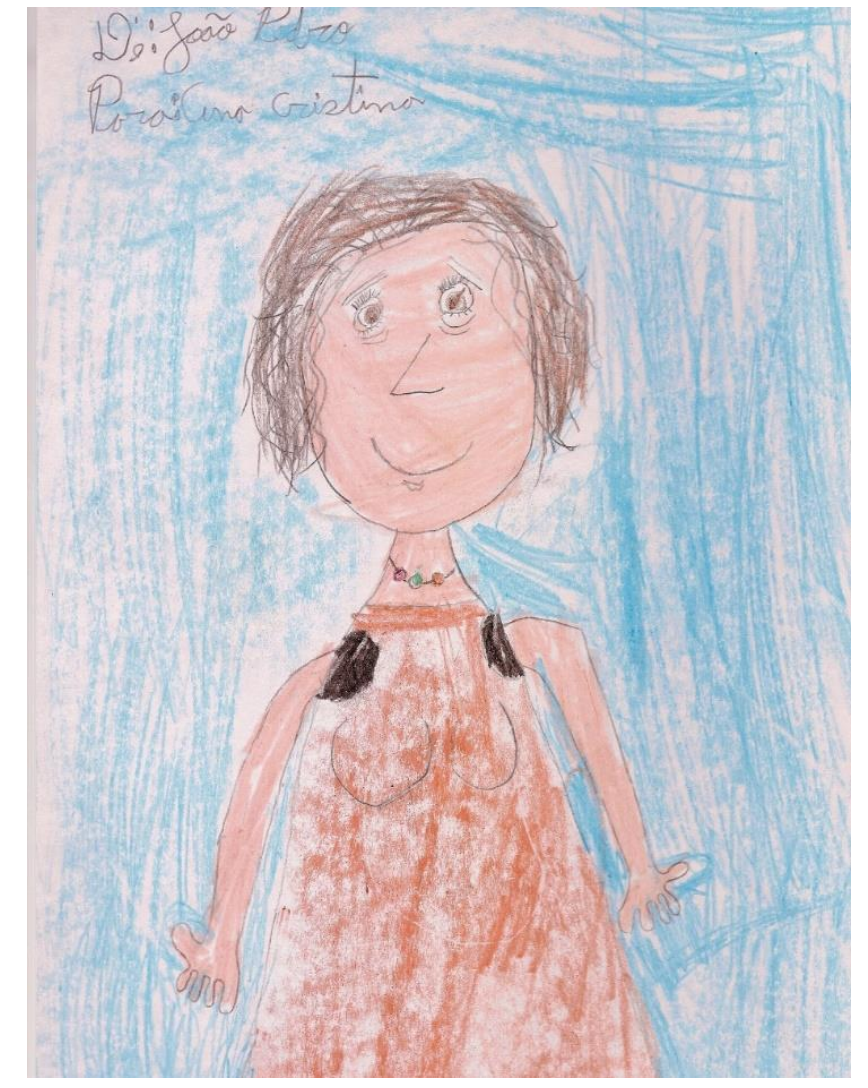

Figura 01. Retrato de despedida. Acervo da autora.

\section{Uma escola de iniciação artística}

"Os lugares que conhecemos não pertencem tampouco ao mundo do espaço, onde os situamos para maior facilidade".

(Marcel Proust) 
A EMIA pertence à Secretaria de Cultura da Prefeitura de São Paulo e tem como proposta a iniciação de seus alunos às áreas artísticas, abarcando as áreas de artes visuais, dança, música e teatro de maneira integrada. A escola ocupa três casas localizadas dentro de um parque público: o Parque Lina e Paulo Raia, no bairro do Jabaquara, na cidade de São Paulo. Ela atende, no Curso de Iniciação Artística, em torno do qual sua estrutura é organizada, a crianças de cinco a doze anos. As aulas desse curso são semanais e sua duração depende da faixa etária dos alunos, variando de duas a três horas e meia. Para os alunos de cinco a oito anos as aulas são dadas em parceria por uma dupla de professores com formação em linguagens artísticas diferentes, sendo que as combinações de linguagem que constituem a dupla não correspondem a nenhuma intenção prédeterminada e não são informadas aos pais no ato da matrícula anual; aos nove e dez anos os grupos são orientados por um quarteto de professores, cada qual com formação em uma das quatro linguagens trabalhadas pela escola; aos onze e doze anos há apenas um professor, especialista na área de opção do aluno.

O Curso de Iniciação Artística é a única atividade obrigatória para os alunos matriculados na EMIA. Mas além dele, a escola oferece, dependendo da disponibilidade de vagas, cursos optativos de foco mais específico: instrumento musical, dança, teatro e artes visuais. Atividades abertas à comunidade e aos ex-alunos são as oficinas, orquestra, conjuntos e corais. O ingresso é feito por meio de um sorteio público, já que a demanda excede largamente o número de vagas. Qualquer criança pode se inscrever para esse sorteio, não havendo qualquer teste de aptidão. Atualmente a EMIA tem por volta de mil alunos matriculados no Curso de Iniciação Artística e mil e seiscentos, no total, incluindo aqueles que frequentam as atividades abertas à comunidade.

Tal estrutura foi sendo construída pela equipe através dos anos, em um processo contínuo de observação, adequação e readequação das propostas. Também os princípios da escola - como a ênfase na criação e no fazer artístico da criança, o respeito às singularidades de cada aluno em seus tempos e modos de participar, aprender e criar, a integração das linguagens e a valorização da figura do professor-artista ${ }^{2}$ - o professor envolvido com a criação na própria linguagem que ensina (ROCHA, 2011) - têm sido discutidos e recriados, incorporando no curso do tempo outros vocabulários e saberes que vêm a provocar novas proposições.

\footnotetext{
${ }^{2}$ Na minha dissertação de mestrado, incluída nas Referências Bibliográficas, trabalhei a concepção do professorartista.
}

Revista Digital do LAV - Santa Maria - vol. 11, n. 2, p. 40 - 61 - mai./ago. 2018 ISSN 1983 - 7348 http://dx.doi.org/10.5902/1983734833896 
Fui contratada como professora de música alguns meses antes da escola ser inaugurada, em 1980, enquanto ainda cursava a graduação em música. Desse modo, vivi o momento inaugural da escola numa época em que me iniciava profissionalmente, dando oportunidade a que na minha vida indubitavelmente se manifestasse a iniciação apontada no nome da instituição. Atuei como professora de musicalização, de instrumento e de conjunto; fui coordenadora da área de música e assistente de direção. Pude participar da história e processo de construção da escola; formei-me, ou, melhor, engendrei um modo de ser professora e artista nos encontros com as crianças, colegas e comunidade- um modo também afetado e alimentado por outras linhas de vida e criação. No meu percurso como musicista e educadora musical outros círculos de envolvimento artístico e profissional se movimentaram, e até hoje continuam em movimento. Mas durante todo o período da minha relação profissional com a EMIA, o ambiente da escola se constituiu para mim em referência, espaço de interlocução e construção de conhecimento artístico e pedagógico. Desse modo, em uma dimensão muito íntima, um desdobramento da questão que eu colocava em relação aos ex-alunos pulsava em mim: de que forma ecoaria toda essa experiência vivida? Como as possibilidades que eu construíra nesse ambiente se recriariam no novo ciclo que a mim se anunciava?

Foi habitando essa zona de passagem que me lancei à pesquisa.

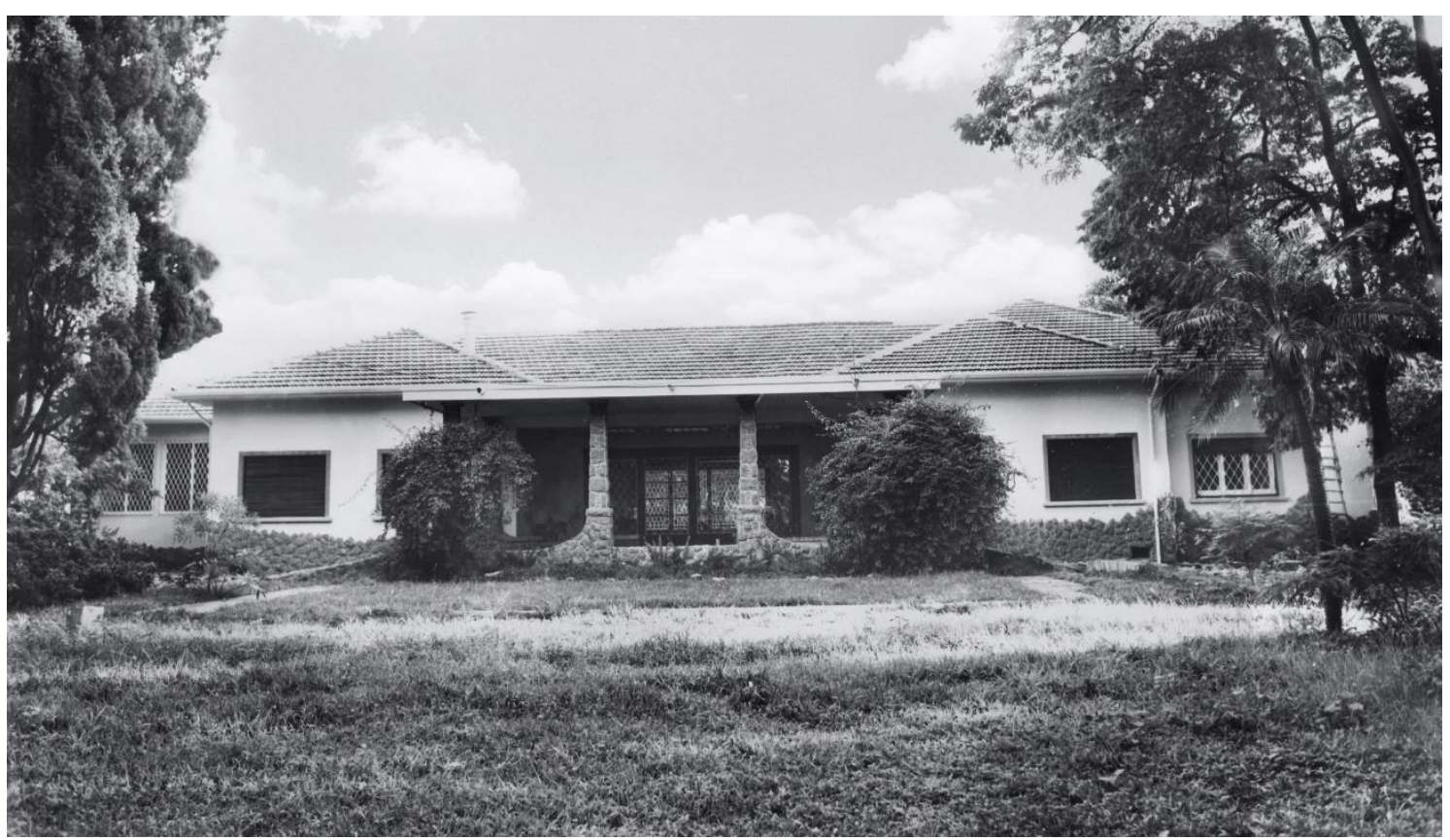

Figura 02. Casa 3, anos 1980. Acervo EMIA 35 Anos.

Revista Digital do LAV - Santa Maria - vol. 11, n. 2, p. 40 - 61 - mai./ago. 2018 ISSN 1983 - 7348 http://dx.doi.org/10.5902/1983734833896 


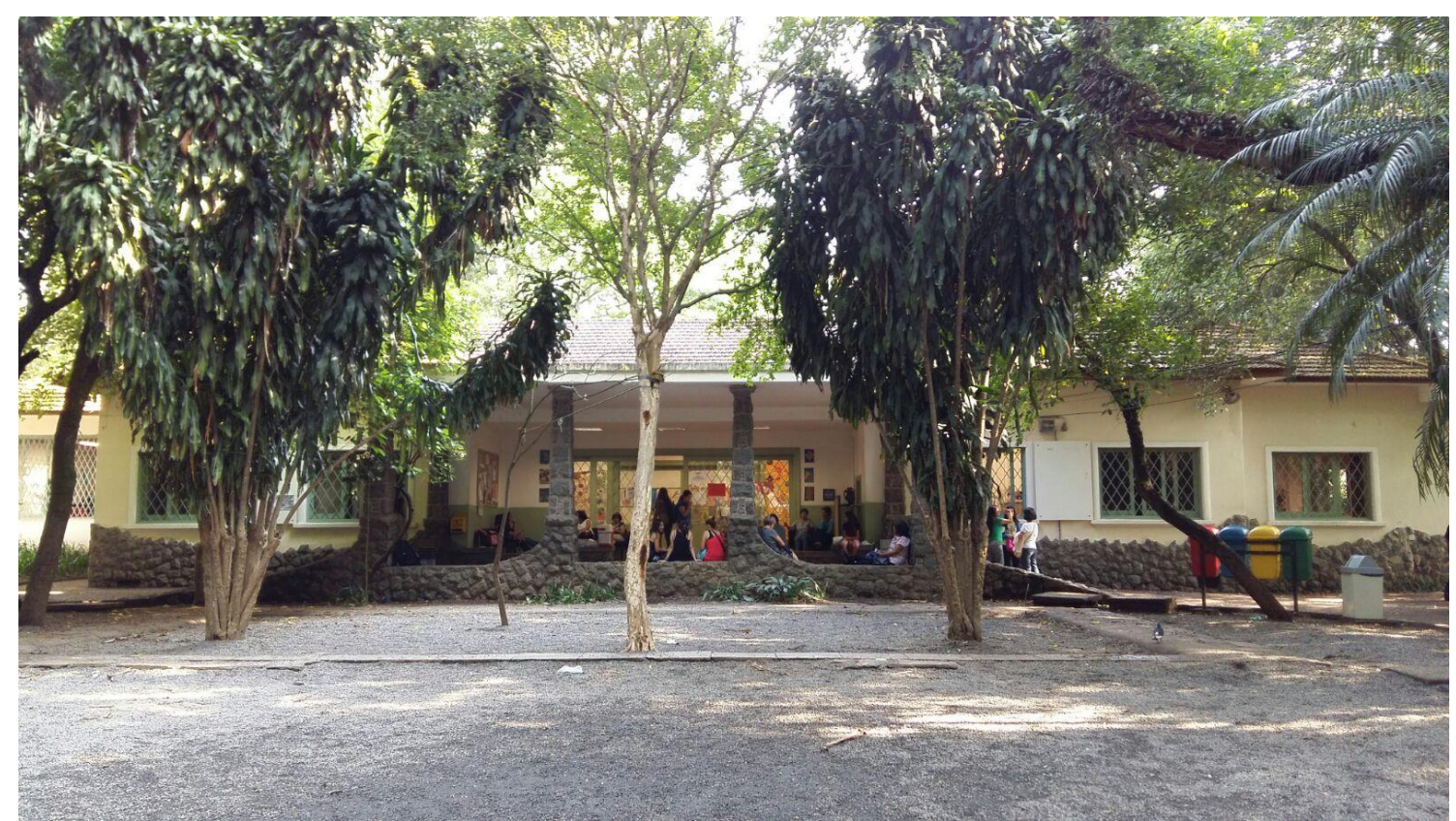

Figura 03. Casa 3, 2015. Acervo EMIA 35 Anos, foto Liseti Bonamin.

\section{Em campo}

Ao iniciar a pesquisa de campo, não havia definido quantas entrevistas seriam realizadas, embora tivesse clareza quanto à sua concepção como também ao que concernia aos procedimentos de tratamento e análise dos dados.

A primeira entrevista surpreendeu-me pela riqueza e intensidade do relato, impressão ainda ampliada no processo de transcrição e na realização de uma segunda sessão. Mais duas entrevistas foram feitas, e o mesmo me sucedeu - em cada entrevista se descortinava um mundo e múltiplas possibilidades de exploração. Constatei que não seriam muitas mais as entrevistas a serem realizadas. Porém, ao mergulhar na análise dos relatos e na tessitura das relações, percebi que de fato as três entrevistas eram a matéria exata para a composição do trabalho - para que a trama de relações fosse densa e significativa, e, também, honrasse as possibilidades oferecidas pelos relatos. Portanto, os três entrevistados não foram escolhidos a priori, por representarem algum traço em comum, ou, ao revés, por se diferenciarem. No texto da tese, cada um deles é apresentado de modo que o leitor possa compreender por quais caminhos vieram a compor essa trindade.

Muitas outras vozes povoaram o meu exercício de pesquisa. Em 2015 a EMIA completou trinta e cinco anos de história, marco celebrado por um ciclo de comemorações durante o qual meus encontros com ex-alunos puderam se intensificar. Nas festas e eventos da 
escola, eu, já aposentada, estava em campo; e, se não pude incorporar no corpo do trabalho todas as histórias, memórias e imagens compartilhados, certamente tudo isso impregnou a minha percepção, deslocando certezas e afetando o meu pensar - como pistas que me orientavam nos caminhos exploratórios de pesquisa, caminhos plurais de uma cartografia que se compunha no próprio caminhar:

O desafio é o de realizar uma reversão do sentido tradicional de método - não mais um caminhar para alcançar metas prefixadas (metá-hódos), mas o primado do caminhar que traça, no percurso, suas metas. A reversão, então, afirma um hódos-metá. A diretriz cartográfica se faz por pistas que orientam o percurso da pesquisa sempre considerando os efeitos do processo do pesquisar sobre o objeto da pesquisa, o pesquisador e seus resultados (PASSOS; BARROS, 2015, p. 17).

\section{Da coleta à composição das narrativas}

Os meus procedimentos metodológicos foram referenciados pelo campo da História Oral e pelo campo das Histórias de Vida, que se agregaram ao meu interesse pela via da pesquisa cartográfica. A composição das narrativas teve como principal inspiração e referência o trabalho e o pensamento de Walter Benjamin. Na minha experiência, tais referências agregaram-se tanto por suas diferenças como pelos pontos de contato e aproximação - de fato, potencializaram uma à outra. No texto da tese, entretanto, procurei dar a cada uma delas diferenciação e substância.

As questões relativas à ética do pesquisador envolvem aspectos sutis que se refletirão prontamente na relação com os entrevistados, na realização das entrevistas, nos procedimentos de análise e na própria produção da investigação. Aos desavisados, a coleta de depoimentos pode parecer um processo simples. Pode lhes parecer que basta "chegar simplesmente a uma pessoa, pedir-Ihe que conte sua vida ou dê sua opinião" (QUEIROZ, 1953, p. 161). Entretanto, o ato de pesquisa começa na construção de uma postura sensível e flexível, disponível a perceber a potencialidade de histórias que contêm toda e qualquer vida. Lembrando as palavras de Portelli, "O respeito pelo valor e pela importância de cada indivíduo é, portanto, uma das primeiras lições de ética sobre a experiência com o trabalho de campo na História Oral" (PORTELLI, 1997b, p. 17).

Assim, todos os cuidados importam. As cartografias desenhadas neste trabalho foram sendo delineadas desde o primeiro contato com os entrevistados. Ao fazer o convite, coloquei o tema da maneira mais ampla que pude. As entrevistas realizadas foram entrevistas não diretivas - as entrevistas muito estruturadas "tendem a confirmar a moldura de referência prévia do historiador. O primeiro requisito, por isso, é que o pesquisador "aceite" o informante e dê prioridade ao que ela ou ele deseje contar de 
preferência ao que o pesquisador quer ouvir" (PORTELLI, 1997a, p. 35). Em cada uma das sessões, o próprio fluxo do rememorar permitiu que as questões emergissem, efetuando afetos e provocando a produção de sentidos; a cartografia de cada um dos entrevistados, como toda cartografia, "foi se fazendo ao mesmo tempo que certos afetos foram sendo revisitados (ou visitados pela primeira vez) e que um território foi se compondo para eles" (ROLNIK, 2011, p. 26).

Antes de cada encontro, procurava me preparar exercitando uma espécie de esvaziamento em relação a expectativas e ansiedades quanto aos resultados. O cartógrafo necessita chegar a campo sensibilizado por esse trabalho preparatório. Esse trabalho ativo sobre as próprias expectativas e projeções necessita ser estendido a toda a entrevista - e é um trabalho tão delicado quanto fundamental para que a nossa presença adquira uma qualidade de permeabilidade, propícia à ativação "de uma atenção à espreita - flutuante, concentrada e aberta" (KASTRUP, 2015, p. 48).

As entrevistas foram realizadas em duas sessões. Entre uma e outra, realizava as transcrições. Ressalto a importância desse momento da pesquisa: a artesania que envolve a transcrição não deve ser tomada apenas como um meio para se obter o material escrito - ela é em si investigação: escutar várias vezes um trecho por conta de uma palavra que teima em escapar, ou para captar a vibração de um riso, a emoção mais intensa que atravessa uma palavra, as interrupções e os silêncios.... Trata-se de um trabalho longo, minucioso, mas imprescindível para que as palavras não se descolem do sentido que as provocou. Após as transcrições, e com constantes revisitações ao material bruto, os relatos foram tratados narrativamente. As narrativas, em sua forma acabada, foram submetidas à aprovação dos entrevistados.

$\mathrm{Na}$ composição das narrativas as vozes dos entrevistados me acompanhavam, ressoando em torno e dentro de mim - as narrativas construíram-se afetadas por seus modos de relembrar, expressar e pensar. Mergulhei na experiência de dar forma, adensar, reunir, encadear; de "mergulhar na geografia dos afetos e, ao mesmo tempo, inventar pontes para fazer sua travessia: pontes de linguagem" (ROLNIK, 2011, p. 66). Por todos esses gestos, como nos anuncia Benjamin no célebre texto "O Narrador" (BENJAMIN, 2012), incorporou-se à narrativa a marca da narradora, algo de seu estilo e feição. Desinteressada em "transmitir o "puro em si" da coisa narrada, como uma informação ou um relatório" (BENJAMIN, 2012, p. 221), à narrativa também não interessa esgotar o tema ou assunto. Sua natureza é a do encadeamento: "cada história é o ensejo de uma história, que desencadeia uma outra, que traz uma quarta, etc." (GAGNEBIN, 2012, p. 13). 
Além das entrevistas, os e-mails da nossa correspondência, publicações no Facebook, o TCC de Carolina e os relatórios apresentados por Júlia ao cursar a disciplina Estágio Supervisionado I (FE - UNICAMP) ${ }^{3}$ constituíram-se em fontes de pesquisa.

Tanto Júlia quanto Carolina, em períodos diferentes, ingressaram na EMIA aos cinco anos. Júlia completou o Curso de Iniciação Artística, e Carolina deixou de frequentar a escola como aluna regular um ano antes do término do Curso.

Júlia e eu não nos lembrávamos de ter tido algum contato direto anterior à entrevista. Mas há alguns anos eu ouvia comentários sobre ela: Júlia, uma ex-aluna da escola, havia se graduado em Artes Visuais no Instituto de Artes da UNICAMP, e realizado parte das disciplinas de licenciatura na Faculdade de Educação da mesma universidade. Mais tarde, soube que ela estava atuando no PIÁ ${ }^{4}$ - Programa de Iniciação Artística da Prefeitura de São Paulo; e, finalmente, que havia sido contratada como professora da EMIA. Não fomos colegas por um triz, pois quando ela iniciou sua atividade profissional na EMIA eu havia acabado de me aposentar.

Carolina foi minha aluna de flauta doce dos sete até os doze anos. Depois, como ex-aluna, continuou a participar por três anos do Conjunto de Flautas da EMIA que eu dirigia. Assim, nossa relação aluna-professora iniciou-se em 1996, estendendo-se com regularidade até 2004. Ela continuou seus estudos musicais na Escola Municipal de Música - EMM (instituição hoje denominada Escola de Música de São Paulo). Mais tarde soube que havia optado pela música como campo profissional e ingressado no Curso de Música - Licenciatura, da Escola de Comunicações e Artes da USP. No decorrer do tempo tivemos alguns contatos e trocamos e-mails, que vieram a compor uma espécie de correspondência; e nos reencontramos em virtude do seu Trabalho de Conclusão de Curso, intitulado "O que aconteceu? Um Relato sobre formação e educação musical" (CASTRO, 2014) ${ }^{5}$, para cuja banca de defesa fui convidada. Ao me escrever um e-mail fazendo esse convite, ela assim se pronuncia sobre o seu TCC: "É uma busca por, a partir das minhas memórias e da revisitação da minha trajetória como aluna, entender como eu estruturei meu pensamento e minhas ideias sobre ser professor".

\footnotetext{
${ }^{3}$ Disciplina Estágio Supervisionado I. Docente Ana Angélica Albano - FE - UNICAMP. Relatório entregue à docente da disciplina em julho de 2007.

${ }^{4}$ O PIÁ é um programa gerido pela Secretaria Municipal de Cultura com parceria orçamentária da Secretaria Municipal de Educação, oferecido para crianças e adolescentes de 05 a 14 anos. Inspirado na EMIA, existe há nove anos e acontece de forma descentralizada em CEUs, Bibliotecas, Centros Culturais, Teatros, Casas de Cultura e Escolas.

${ }^{5}$ CMU- ECA- USP, 2014. Orientador Pedro Paulo Salles.
} 
Os encontros com os entrevistados e o trabalho de composição das narrativas proporcionou-me a tessitura de uma rede de sentidos. Uma rede que pôde ser tramada sem fazer uso dos pontos largos e superficiais dos lemas e da reafirmação de certezas. Desse conjunto de relações, compartilho recortes de uma das camadas de significação acessadas e analisadas no trabalho.

\section{Ser percebido}

\section{Júlia}

Encontrei na UNICAMP várias pessoas que também tinham feito EMIA. A Elisa, por exemplo, era da minha turma e se tornou uma grande amiga. Eu não lembrava dela, nem ela de mim. Mas conversa vai, conversa vem... Conversando com ela sobre a EMIA, eu disse: - "A gente era "ouvido!" não era?". E ela: -"Nossa! Eu sempre senti exatamente isso!". Por mais que se trate de arte, existia também um trato social que não encontrei em outras escolas, em lugar nenhum. Cada um tem seu tempo na roda e é ouvido; não importa o que a pessoa está falando, importa que ela é ouvida. Isso é muito importante em uma escola; e na minha formação foi fundamental - você aprende que todo ser humano tem valor; coisas muito ricas, aprendi aqui. Como? Acho que por isso, por ser ouvido. Sentia que a gente era respeitado por aquilo que fazia, era olhado, às vezes isso na escola formal se esvazia (Júlia).

Por mais que se trate de arte, existia também um trato social... Um trato: um acordo, um pacto, um ajuste. Dentro desse trato, a prática da conversa é a prática de uma fala livre, e não liberada; e, como prática, precisa ser exercitada. Na EMIA, a roda de conversa é uma prática comum a muitos professores. As crianças também interferem naturalmente na regulação desse jogo, que a meu ver não funciona e perde o interesse sem essa regulação, mas que também não funciona se regrado demais, engessado por um excesso de determinações. Tal regulação se configura como uma construção do grupo e pode se inserir numa concepção ampla do exercício das práticas de liberdade, na acepção de Foucault (2010).

Fui surpreendida pela intensidade e contundência da fala de Júlia, na qual pulsava um conteúdo vivido e ampliado: ser ouvida e perceber que todos os colegas eram ouvidos havia sido experiência fundadora de aprendizados fundamentais. Espantei-me com a constatação da potência de um gesto aparentemente tão simples, e com o relevo que Júlia Ihe dava - pois não deveria ser a escuta inerente ao ato pedagógico? Por que então ela facilmente nos escapa, tornando-se algo raro e difícil de se encontrar? 
Mais adiante, Júlia relaciona essa rememoração à sua prática como educadora: dar aula também é um exercício desse conhecimento. De que todo mundo tem coisas para dar, que todo mundo consegue fazer as coisas, em um tempo maior ou menor. Dar aula é um exercício, porque sempre tem um aluno que foge da nossa expectativa; e a gente vai precisar se rever para poder dialogar com ele (Júlia).

Perceber e escutar a todos os alunos, como também acolher e qualificar seus trabalhos e produções expressivas, não significa deixar de perceber as diferenças que as singularidades expressam: A EMIA trouxe o social. [...] estar num grupo desenhando trouxe uma coisa que eu ouvi bastante dos professores de artes visuais, uma coisa chamada "talento". O professor colocava os trabalhos dos alunos, observava coisas, e eu ia sentindo isso (Júlia).

Acolher tendências, dialogar com as manifestações e produções da criança expressando nossas percepções de maneira simples e concreta, é muito diferente de mistificar seu talento e enaltece-lo diante dos colegas e diante dela mesma - o que seria prejudicial para todos. Em "Tuneu, Tarsila e outros mestres..." o pintor Antônio Carlos Rodrigues, o Tuneu, relata a Ana Angélica Albano que, em sua adolescência,

desenhava muito. E desenhava bem mesmo. Eu tinha uma facilidade tremenda [...]. As pessoas percebiam que eu sentava, e aquilo vinha, e tudo isso era muito valorizado. Não para eu ser artista. Eles viam um show e gostavam. [...] queriam reduzir a amenidades, ao virtuosismo, coisas que para mim não tinham o menor sentido (ALBANO, 1998, p. 55-56).

A receptividade dos professores não determinou a escolha de Júlia quanto ao seu caminho profissional; mas, fazendo ressoar possibilidades, "ativando seus processos de formação" (ALBANO, 1998, p. 126), agregou-se a um conjunto de sensações, impressões, e experiências pelas quais ela pôde se orientar: $E$ eu, criança, fui me sentindo mais segura nessa área de artes visuais, acho que isso também contribuiu para o meu caminho. Eu sentia que entendia o que essas pessoas falavam; mais do que os elogios, foi essa sensação de estar entendo uma conversa. Fui percebendo que por ali eu podia... mesmo que eu também gostasse de outras coisas. Na aula de teclado, por exemplo, eu inventei uma música japonesa que eu nunca esqueci, me apresentei tocando essa música, minha família até hoje se lembra (Júlia).

Mais velha, depois de ter saído da EMIA, os signos das artes visuais continuaram a atrair a atenção de Júlia; o colégio em que ela estudava oferecia aulas de arte e de História da Arte, mas, mesmo assim, ela queria mais: então comecei a ir a exposições sozinha. Eu

Revista Digital do LAV - Santa Maria - vol. 11, n. 2, p. 40 - 61 - mai./ago. 2018 ISSN 1983 - 7348 http://dx.doi.org/10.5902/1983734833896 
morava perto do autódromo de Interlagos; pegava o ônibus e ia para o centro, ao Centro Cultural Banco do Brasil, Pinacoteca, ia ao MASP, ficava fuçando, via no jornal e ia. E também ia "comendo" livros de História da Arte. Eu me apaixonei. Disse para minha mãe que não ia ter jeito: não era arquitetura, era arte (Júlia).

Certamente ninguém pode ensinar ninguém a se apaixonar. Os signos vibram para cada um de nossos alunos de modo singular e intransferível e cabe a eles eleger os que lhes são próprios e lhes dizem respeito. Mas, principalmente, enquanto vivem a infância das suas afinidades e eleições, podemos procurar facilitar e incitar os encontros e as experiências nesse sentido e acolher as tendências que ensaiam se manifestar. Ter, em plena infância, sido percebida e ter sentido que entendia o que essas pessoas falavam, não determinou, mas contribuiu fortemente para que Júlia se entregasse à sua busca e à sua paixão.

Ela agora vive esse papel como professora: Eu tenho um aluno, o Inácio, que cria umas roupas, objetos, pinta o corpo, e eu falei para ele que ele devia continuar fazendo essas pesquisas. Então eu fiz a mesma coisa, para o bem e para o mal... Não sei se é bom ou não, a gente nunca sabe. Mas se eu vi uma coisa ali, acho que tenho de falar, é uma cumplicidade (Júlia).

E experimenta como cada criança necessita de estímulos diferentes: o ano passado eu tive um aluno que tinha um senso de "construção"!!! A La Michelangelo! Sabe aquele lance de olhar a pedra e já ver o que tem lá dentro? (...). Não falei nada para ele, porque... ele já sabe. (...). Já me aconteceu várias vezes. De olhar um trabalho e pensar: nossa, esse menino sabe muito mais do que eu (Júlia).

\section{Carolina}

Em 2010 recebo de Carolina um e-mail:

27 de agosto de 2010

Oi, Ana, tudo bem?

Aqui é a Carol que foi sua aluna de flauta na EMIA há uns aninhos! Ontem eu fiquei até inconformada que não tinha o seu telefone, porque foi a minha primeira aula de flauta (como professora, dessa vez!), e eu queria muito te contar [...]. Já na primeira aula, eu mostrei uma música nova (aquela Dois por $D^{6} z^{6}$, dos biscoitinhos, a primeira que eu aprendi!) para a Helena, que tem 7 anos (exatamente a minha idade, quando comecei) e

\footnotetext{
${ }^{6}$ Dois por Dez - melodia que tem sua origem em um antigo pregão inglês.
} 
ela gostou muito. Ela disse que os biscoitinhos da música são como os biscoitinhos do Shrek?! O Felipe, que também tem 7 anos está escrevendo uma história de monstros e nós vamos sonorizar. Cada aula ele traz mais um pedacinho novo da história. Depois da aula várias lembranças gostosas passaram pela minha cabeça [...].

Ao me escrever para contar sobre a experiência da primeira aula como professora, Carolina reatualiza suas memórias. E entre as lembranças gostosas chamou-me a atenção o fato dela destacar uma memória extramusical: Você pediu um caderno [...] e eu trouxe um caderno que usava para escrever umas histórias de vez em quando. Quando não tinha história nova você estranhava, me perguntava por que eu não tinha escrito (Carolina). Nossa escuta dos alunos envolve toda a nossa observação e se estende aos cuidados que podem se manifestar das mais variadas formas, como em um simples gesto de interesse e atenção. Atentar ao caderno, interessar-me sinceramente pelas histórias de Carolina, e não para cumprir uma determinação pedagogicamente correta, foi gesto que fertilizou o vínculo entre a aluna e a professora, que ensaiava germinar.

Entrar em contato com essa reminiscência fortaleceu a minha conviç̧ão de como pequenos detalhes e delicadezas compõem uma postura e podem ser mais importantes do que se pode imaginar. Esses cuidados se agregam e potencializam as proposições artísticas próprias ao nosso campo, e as oportunidades que oferecemos à participação e protagonismo das crianças. Ao destacar no seu TCC a memória de uma canção tradicional chilena, Carolina narra que Ela é um exemplo de uma prática que frequentemente acontecia nas aulas de flauta: fazer arranjos de canções nos quais eu tocava e cantava. Eu gostava muito de cantar, e essa música se tornou especial por considerá-la uma das mais bonitas, mas também porque, em uma das aulas, minha irmã mais nova quis entrar para assistir e ela acabou fazendo parte do arranjo, cantando. Em um trecho, cantávamos as duas juntas, em espanhol e em português. No fim, deu tão certo que a audição de alunos seguinte teve a participação especial de minha irmã em "Uma flor de laranjeira" (CASTRO, 2014, p. 21).

Ela também se refere em seu trabalho a uma melodia composta enquanto andava pela casa explorando a flauta. Na aula seguinte, ela ganhou um solo final de claves (CASTRO p. 28). Aos poucos me recordei que ela me mostrou a música, tocando, eu a acompanhei no processo de escrita da melodia no caderno, e nos veio a ideia das claves. Desde que participara com seu grupo de quarteto da gravação do CD da EMIA [....] como solista nas claves na faixa "Samba na areia", de Pixinguinha, as claves se tornaram um de meus

\footnotetext{
${ }^{7}$ Shrek - personagem protagonista de quatro filmes de animação PDI/DreamWorks.
} 
instrumentos preferidos. Era vantajoso preferir claves, pois nenhum outro aluno gostava delas, dessa forma não ocorriam conflitos no momento de escolher os instrumentos [...] " (CASTRO, 2014, p. 28-29).

A oportunidade de participar da gravação de um CD, com o instrumento de eleição, no qual ela - ao contrário de todos os outros colegas - percebia vantagens e possibilidades, a exploração e a invenção da melodia em casa, a escrita da melodia na aula de flauta, a ideia do solo: experiências vividas nas diferentes atividades que se entrecruzaram e fortaleceram uma à outra.

Ao rever no TCC a partitura da melodia Sol de Primavera, reconheço a caligrafia musical de Carolina, pontuada por uma ou outra intervenção minha. Aflora-me aos poucos uma memória que me sorri, lá do fundo do tempo: o evento da ideia da improvisação de claves nos provocando alegria.

Ela está apontada no final da melodia na minha letra, muito apertada, vazando do pentagrama para a margem, (talvez porque o pentagrama seguinte já estivesse ocupado), insignificante demais, quase um rabisco. Mas pelos meus olhos de hoje, poetizados pelas memórias e significações de Carolina, às quais se agregam as minhas, percebo nessa fragilidade do rabisco apertado a potência que pode haver numa pequena janela de invenção, apertada no papel, mas aberta à invenção e à novidade.

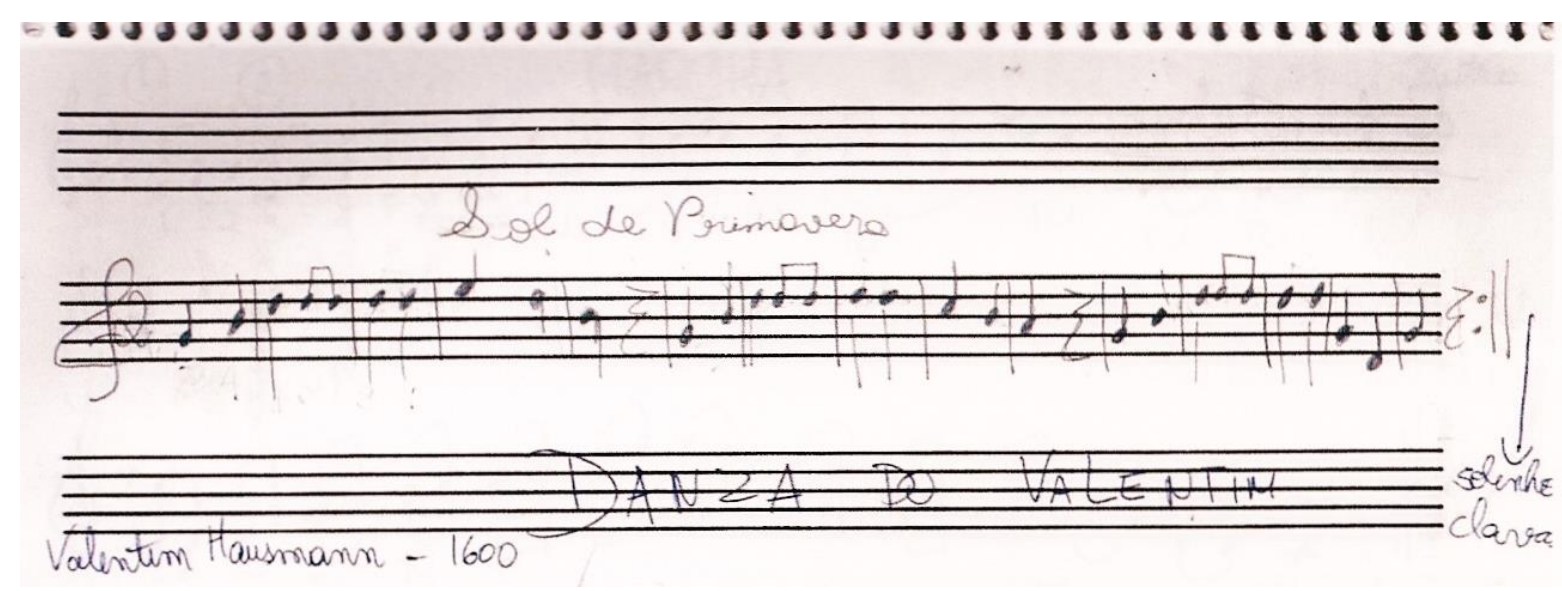

Figura 04. Sol de Primavera, fragmento do caderno de flauta analisado no TCC de Carolina. 
Júlia e Carolina, nos movimentos de rememorar e ressignificar a própria experiência: ser percebido e perceber ao outro, ser acolhido e acolher, abrir-se à escuta e ser ouvido, criar e potencializar a criação do outro. Criar-se a si mesmo e proporcionar que o outro também possa se envolver no movimento de criação de si próprio: experiências que se desdobram uma na outra, no tempo exato do desabrochar.

Em relatório para a disciplina Estágio Supervisionado, em 2007, pertinente à sua primeira experiência como professora, Júlia assim conclui suas reflexões e construções de pensamento:

Acredito que minha atuação dentro de sala se assemelha com minha atuação no mundo. Arte para mim é materialização de ideias, creio que dar aula de artes seja permitir que outro materialize suas ideias, descobrindo-as. Transformação da matéria é transformação de energia. Ensinar arte exige crer na arte, crer no mundo visível (Júlia).

Em junho de 2016 leio uma publicação de Carolina no Facebook:

Quando é festa junina, você está trabalhando extra no sábado gelado, e seu aluno de três anos chega correndo na sua barraca isolada, todo empolgado pra mostrar o pandeiro que ele ganhou de prenda e vem tocando com o exato giro de mão esquerda que você faz pra tocar, e você enxerga a sua mão, o seu movimento naquela mãozinha nova que acabou de chegar ao mundo e pensa em quanta coisa que ela ainda não vai trazer e fazer pra cá, que você não consegue sequer mensurar o quão revolucionário e cheio de possibilidades novas o seu dia-a-dia pode ser. Todos os dias.

\section{Entre encontros}

Entre os encontros e as construções, pude viver esta pesquisa como possibilidade de transformação. Labor e criação conjuminados. Na experiência da criação, transformamos a matéria, e a nós também nos transformamos - criar-se, criando. Nas palavras, busquei a matéria de uma escrita que não se arvora em conclusiva ou acabada. Mas que, tomando e transpondo palavras de Bergson, se oferece como "lugar de passagem dos movimentos recebidos e devolvidos", "traço de união entre as coisas que agem sobre mim e as coisas sobre as quais eu ajo" (BERGSON, 1999, p. 177).

\section{Corpo e feição}

\section{Carolina}

[...] da Tássia eu lembro muito porque a gente tocava juntas nas aulas de flauta, nas audições e no conjunto... E mais tarde eu a reencontrei na Escola de Música. [...] Nossa! 
Festa da primavera! Choveu demais! A gente tocou em uma tenda, bem no meio do parque, tinha uma cobertura... (Carolina).

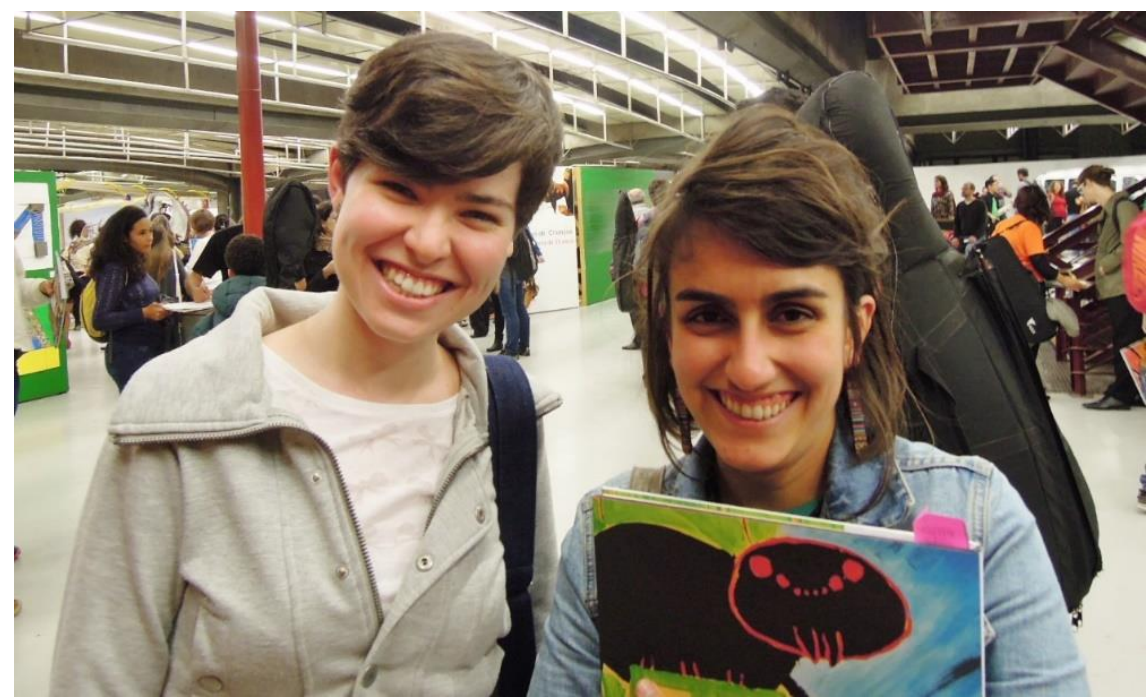

Figura 05. Tássia e Carolina (à direita) na exposição comemorativa dos 35 anos da EMIA. Centro Cultural São Paulo - 04/06 a 17/07 de 2016. Foto da autora.

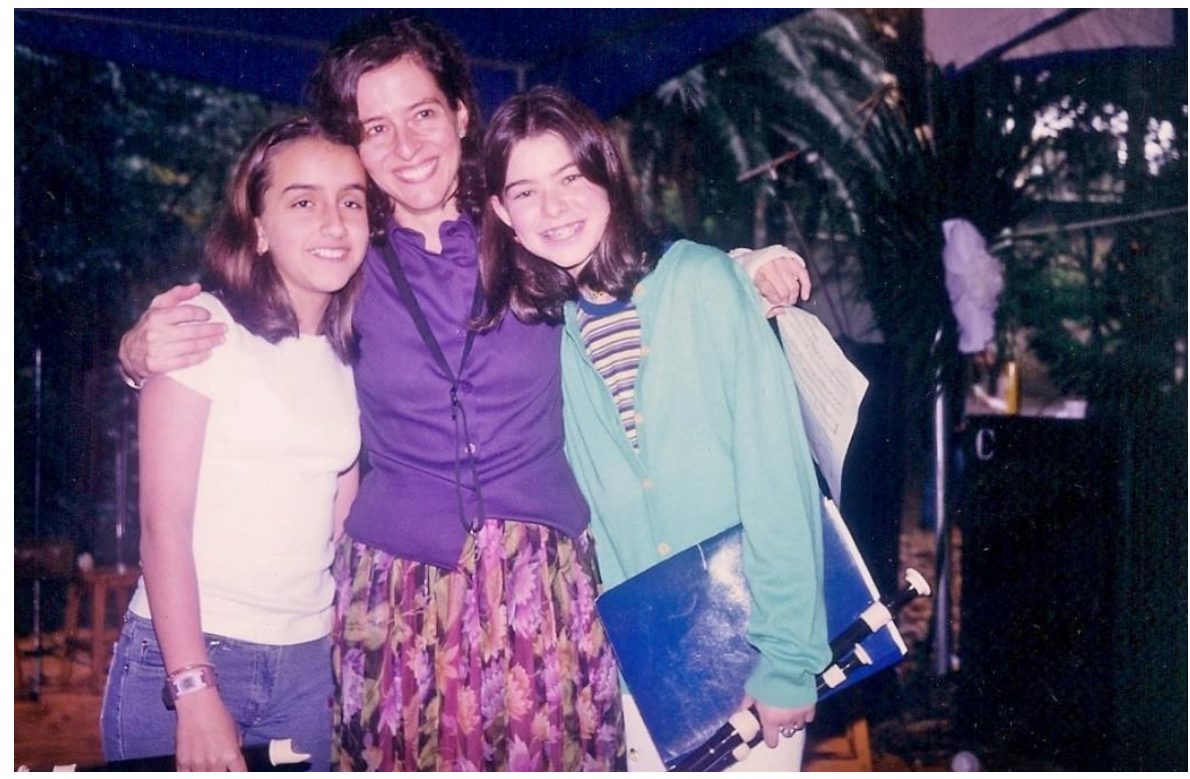

Figura 06. Carolina, eu e Tássia na Festa da Primavera. Parque Lina e Paulo Raia, setembro de 2001. Acervo da autora. 


\section{Júlia}

Minha família é da Andaluzia, tenho cidadania espanhola. Quando eu era criança, minha avó ia e voltava com essa Espanha na mala. Eu vivi isso. De alguma maneira também estou voltando para um lugar de origem. Falo espanhol, catalão vou aprender, espero... Ano passado eu fiz minha primeira individual lá; aqui eu já tinha ido atrás, mas não tinha conseguido. Isso impulsionou, foi uma tremenda realização (Júlia).

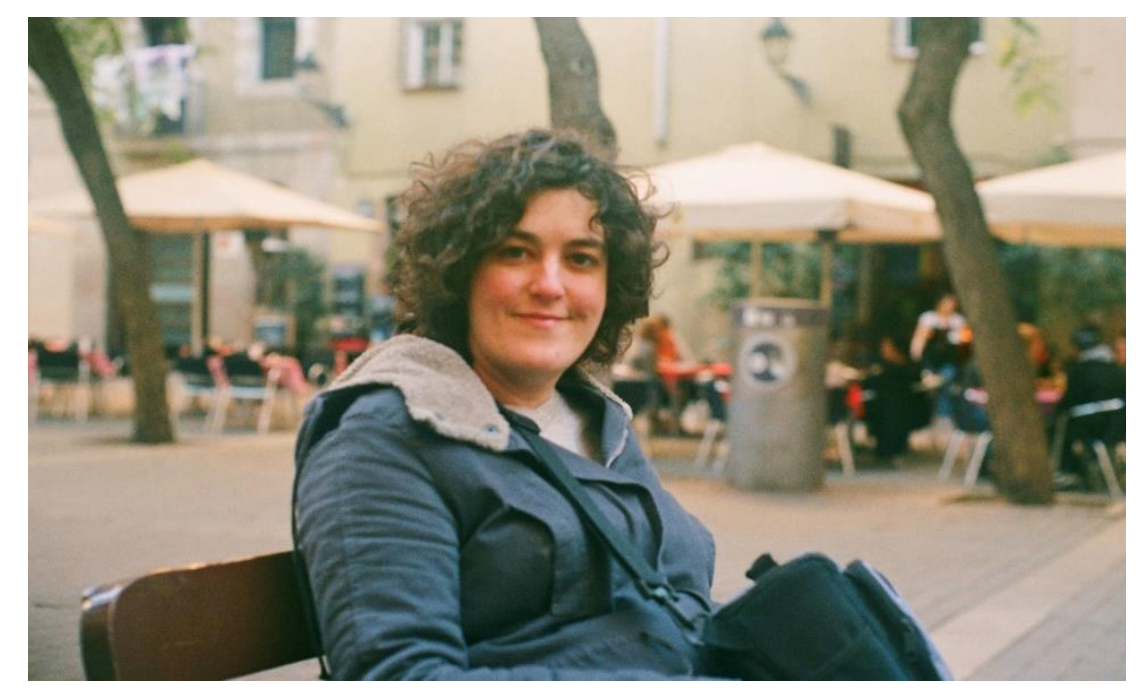

Figura 07. Júlia em Barcelona. Foto Olaia Rodriguez.

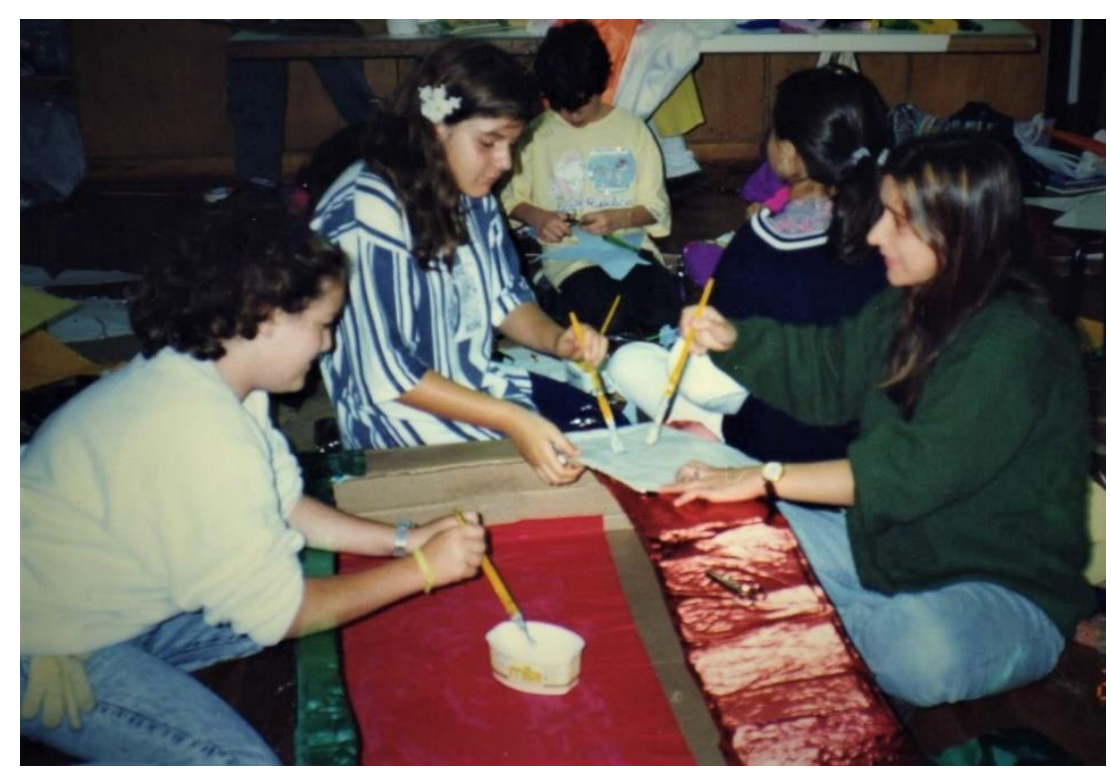

Figura 08. Júlia (à esquerda), aluna das professoras Flávia Ferraz (à sua frente) e Thelma Penteado. EMIA. Foto Thelma Penteado. 


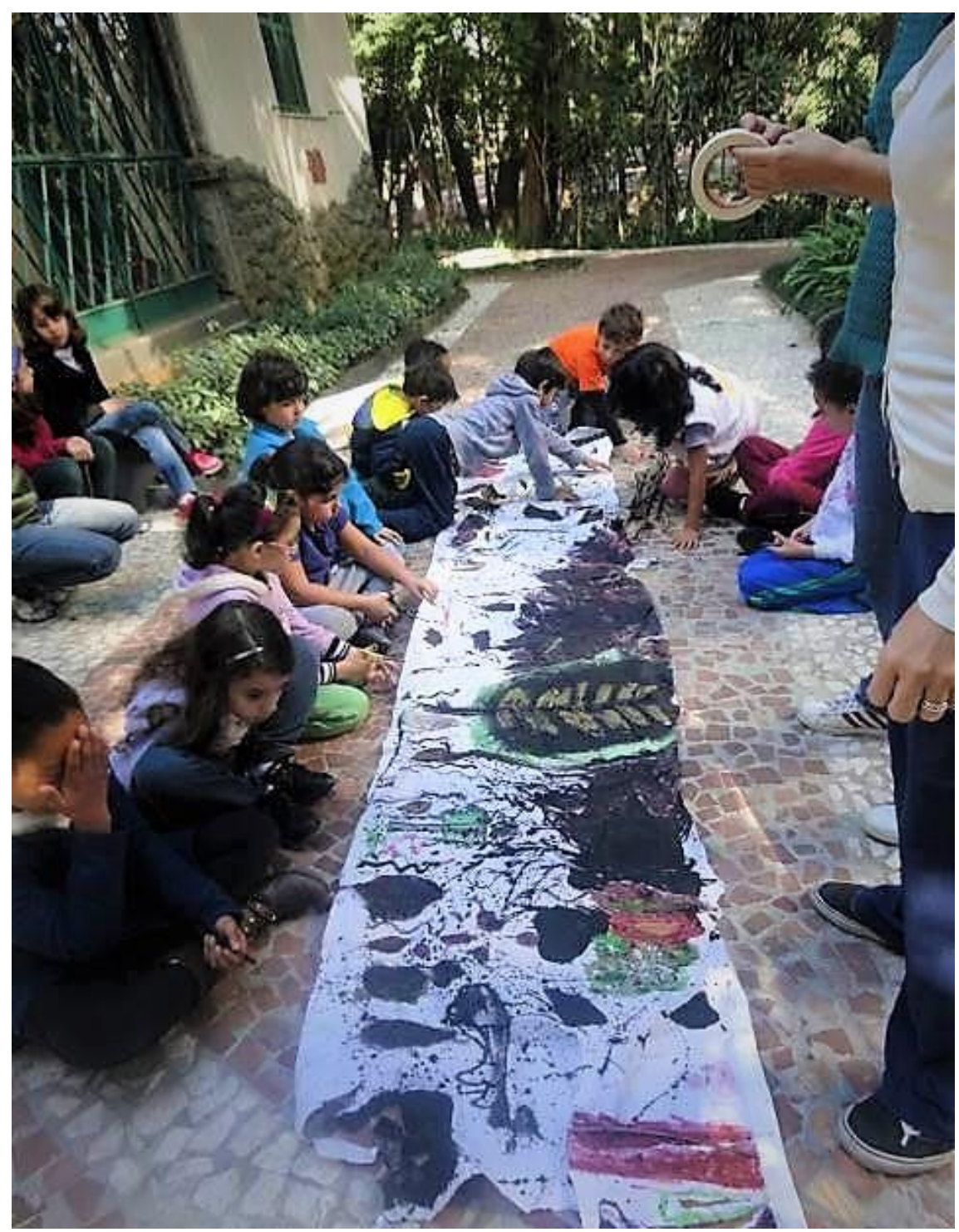

Figura 09. Trabalho coordenado pela dupla de professores Júlia Salgueiro e Renata Facury. Exposição Linhas do Mundo, Galeria EMIA. Foto Júlia Salgueiro.

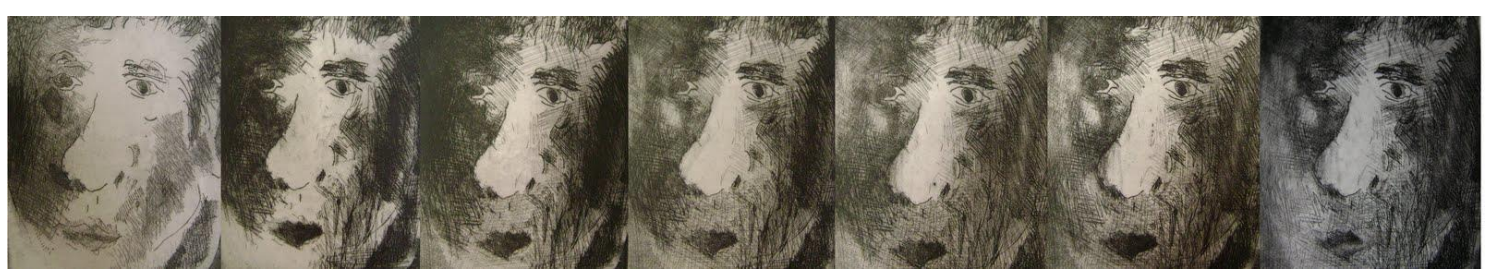

Figura 10. Painel Estados, composto por 19 gravuras em metal - Júlia Salgueiro. 


\section{Referências}

ALBANO, A. A. Tuneu, Tarsila e outros mestres: $O$ aprendizado da arte como um rito de iniciação. São Paulo: Plexus Editora, 1998.

BENJAMIN, W. Magia e técnica, arte e política: ensaios sobre literatura e história da cultura (Obras Escolhidas v.1). São Paulo: Brasiliense, 2012.

BERGSON, H. Matéria e memória. São Paulo: Martins Fontes, 1999.

BERGSON, H. A evolução criadora. São Paulo: Folha de São Paulo, 2015.

CASTRO, C. G. O que aconteceu? Um relato sobre formação e educação musical. São Paulo: CMU- ECA- USP, 2014.

DELEUZE, G.; GuATTARI, F. O que é a Filosofia? 2. ed. São Paulo: Editora 34, 1997.

FOUCAULT, M. A ética do cuidado de si como prática da liberdade. In: MOTTA, M. B. (Org.). Ética, sexualidade, política. 2. ed. Rio de Janeiro: Forense Universitária, 2010.

FOUCAULT, M. A coragem da verdade: o governo de si e dos outros. São Paulo: Editora WMF Martins Fontes, 2011.

GAGNEBIN, J. M. Walter Benjamin ou a História Aberta. Prefácio. In: BENJAMIN, W. Magia e técnica, arte e política: ensaios sobre literatura e história da cultura. São Paulo: Brasiliense, 2012.

GALLO, S. Metodologia do ensino de filosofia: uma didática para o ensino médio. Campinas, SP: Papirus, 2012.

KASTRUP, V. O funcionamento da atenção no trabalho do cartógrafo. PASSOS, E.; KASTRUP, V.; ESCÓSSIA, L. (Orgs.). Pistas do Método da Cartografia. Pesquisaintervenção e produção de subjetividade. Porto Alegre: Sulina, 2015.

PASSOS, E.; BARROS, R. B. A cartografia como método de pesquisa-intervenção. PASSOS, E.; KASTRUP, V.; ESCÓSSIA, L. (Orgs.). Pistas do Método da Cartografia. Pesquisaintervenção e produção de subjetividade. Porto Alegre: Sulina, 2015.

Revista Digital do LAV - Santa Maria - vol. 11, n. 2, p. 40 - 61- mai./ago. 2018 ISSN 1983 - 7348 http://dx.doi.org/10.5902/1983734833896 
PROUST, M. No caminho de Swann. (Em busca do tempo perdido vol. 1). 3.ed. São Paulo: Globo, 2006.

PORTELLI, A. Forma e significado na História Oral. A pesquisa como um experimento em igualdade. Revista do Programa de Estudos Pós-Graduados em História e do Departamento de História. São Paulo, PUC-SP, n. 14, fev., 1997a.

PORTELLI, A. Tentando aprender um pouquinho. Algumas relações sobre a ética na História Oral. Revista do Programa de Estudos Pós-Graduados em História e do Departamento de História. São Paulo: PUC-SP, n. 15, abr. 1997b.

QUEIROZ, M. I. P. Histórias de vida e depoimentos pessoais. Sociologia. São Paulo, v. XV, n. 1, mar. 1953.

ROCHA, A. C. R. Educação musical e experiência estética: entre encontros e possibilidades. Campinas, SP: Universidade Estadual de Campinas, Faculdade de Educação, 2011.

ROCHA, A. C. R. Memórias de iniciação artística e a criação de si. Campinas, SP: Universidade Estadual de Campinas, Faculdade de Educação, 2017.

ROLNIK, S. Cartografia Sentimental. Transformações contemporâneas do desejo. Porto Alegre: Sulina; Editora da UFRGS, 2011.

ULPIANO, C. Manuscrito 14 - Transformar obstáculos em meios. Acervo Claudio Ulpiano, 2017. Disponível em <https://acervoclaudioulpiano.com/2017/08/19/manuscrito-14transformar- obstaculos-em-meios/> Acesso em: 13 maio 2018.

\footnotetext{
' Musicista e educadora musical. Doutora e Mestre em Educação pela UNICAMP, bacharel em Composição pela ECA - USP. Especializou-se no Conservatório Real de Haia, Holanda, como bolsista da CAPES, na área de flauta doce e música antiga. Em seu trabalho focaliza as relações entre a educação musical e a experiência estética, a integração de linguagens artísticas e a produção de subjetividade. Foi professora da EMIA - Escola Municipal de Iniciação Artística (Secretaria Municipal de Cultura de São Paulo) até 2012. Atualmente atua na formação de professores e presta assessoria a projetos e escolas.

Como citar esse artigo:

ROCHA, Ana Cristina Rossetto. Notas acerca das ressonâncias de um processo de iniciação artística na criação de si. Revista Digital do LAV, Santa Maria: UFSM, v. 11, n. 2, p. 4061, mai./ago. 2018.
} 